\title{
Synergistic Inhibitory Effect of Human Umbilical Cord Matrix Mesenchymal Stem Cells-Conditioned Medium and Atorvastatin on MCF7 Cancer Cells Viablity and Migration
}

\section{Reyhaneh Abolghasemi}

Tehran University of Medical Sciences https://orcid.org/0000-0002-2481-6536

Somayeh Ebrahimi-barough

Tehran University of Medical Sciences

Jafar Ai ( $\nabla$ jafar_ai@tums.ac.ir )

Tehran University of Medical Sciences

\section{Research Article}

Keywords: MCF7 Cell Line, Breast Cancer, Proliferation, Migration, Cancer Cells Interactions, Apoptosis, Conditioned Medium, Umbilical Cord Mesenchymal Stem Cell, Atorvastatin

Posted Date: May 3rd, 2021

DOI: https://doi.org/10.21203/rs.3.rs-451918/v1

License: @ (i) This work is licensed under a Creative Commons Attribution 4.0 International License. Read Full License 


\section{Abstract}

Background:

Tumor growth and metastasis eventuate from an interaction between cancer cells and the surrounding extracellular matrix. Recent studies demonstrated inhibitory effects of mesenchymal stem cells on breast tumors. Likewise, the emerging interest in statins as anticancer agents is based on their pleiotropic effects. In the present study, we investigated whether atorvastatin and umbilical cord matrix derived mesenchymal stem cellsconditioned medium alone and combined with each other affect the MCF7 cancer cells viability and interactions.

\section{Methods:}

We measured the viability, apoptosis, and necrosis of MCF7 by MTT assay, Annexin-V/PI staining by flow cytometry, and quantitative real-time PCR. Two-dimensional culture and hanging drop aggregation assay illustrated the morphological changes in single cancer cells and spheroid configuration respectively. We traced the MCF7 migration via scratch-wound healing and trans-well assays.

\section{Results:}

The results showed inhibition of cancer cell viability in all treated groups compared with the control group, but the effect of atorvastatin and conditioned medium combination was further than each one alone. Cancer cells shrinkage and chromatin condensation in the inverted light microscopy and fluorescent staining microscopy indicated apoptosis in treated cells. The annexin V/PI analysis especially in the combination-treated group displayed decreasing in DNA synthesis and cell cycle arrest. The mRNA expressions of caspases 3, 8, 9, and Bcl2 genes were along with extrinsic and intrinsic apoptosis pathways. Conditioned medium disrupts the connections between cancer cells in the three-dimensional spheroids configuration. The migration of treated cells across the wound area and trans-well diminished, particularly in the combination-treated group.

\section{Conclusions:}

For the first time, the synergistic anti-proliferative and anti-motility effect of atorvastatin along with human umbilical cord mesenchymal stem cells-derived conditioned medium on MCF7 breast cancer cells have been proved. These findings point to some new therapeutic strategies with a focus on the crosstalk between breast cancer cells and microenvironment.

\section{Background}

Breast cancer is the most prevalent malignancy of women and the second most common cancer in the world in developed and less developed countries. It is the second cause of cancer death in the female population [1]. Four molecular subtypes have been identified through biological markers. Accordingly, the presence or absence of hormone (estrogen or progesterone) receptors (HR+/HR-) and/or extra copies of human epidermal growth factor receptor 2 genes (HER2+/HER2-) are routinely evaluated. The most prevalent breast malignancy $(71 \%$ of pathobiological types) is luminal A subtype (HR+/HER2-). About $80 \%$ of breast cancer cases are invasive or infiltrating and more than one-third (38\%) of cases are recognized at the non-localized stage [2]. Tumor advancement has been recognized as the result of the interaction between tumor cells and their encompassing supporting stromal cells through direct contact and or in a paracrine manner [3,4]. Michigan Cancer Foundation- 
7(MCF7), a hormone receptor-positive( HR+/HER2-) cell line was isolated in 1973. Many molecular and cellular investigations on breast cancer have been done with this common epithelial adenocarcinoma cell line [5].

Now the main clinical therapy strategies for breast malignancies include surgery, chemotherapy, and radiotherapy. Despite the great success in increasing the survival of patients, they suffer from side effects of treatments and dormant micro metastases remain undetected for years after primary surgery. Cholesterol plays a key role in the structure and function of rapidly dividing tumor cells. Statins are FDA-approved drugs for hypercholesterolemia and are commonly used. Additionally, statins exhibit beneficial pleiotropic effects in other pathologies. Several epidemiological studies have indicated that lipophilic statins reduce breast cancer mortality [6]. Atorvastatin is a synthetic, lipophilic, potent, well-tolerated, and inexpensive statin. Despite widespread usage, less research has been conducted on the effects of atorvastatin on MCF7. Other statins such as simvastatin [7] and other lines such as triple-negative MDA-MB-231 cell line [8] have further been investigated. On the other hand, several studies have postulated the mesenchymal stem cells (MSCs) just as safe, tumor-targeting cellbased therapy [9]. Human umbilical cord matrix-derived mesenchymal stem cells (hUCMSCs) are present in the Wharton's jelly and the tissues surrounding the blood vessels of the umbilical cord [10,11]. The use of supernatant of one cell type, thus named conditioned medium, to another population of cells has been developed as a technique allowing for the study of paracrine signaling in the absence of direct cell-cell contact. The human umbilical cord matrix-derived mesenchymal stem cells-conditioned medium is composed of chemokines, cytokines, proteins, growth factors, and extracellular vesicles which may be involved in cancer cell growth and migration. The hUCMSCs or their supernatant extracts can inhibit the MDA-MB-231 cell growth [12], promote apoptosis, and inhibit colony formation by MCF7 tumor cells [13]. Although, in other study hUCMSCs have promoted the proliferation and migration of MCF7 and MDA-MB-231 cells [14]. Atorvastatin in combination with mesenchymal stromal cells augmented the endothelial progenitor cell proliferation and migration in Qu's study [15] and improved the ischemic cardiac dysfunction in Oktaviono's research [16]. Accordingly, in the present research, we investigated the effect of human umbilical cord matrix-derived mesenchymal stem cells-conditioned medium (CM), atorvastatin(ATO), and the combination of them(CM+ATO) on proliferation and migration of MCF7 cells in-vitro.

\section{Methods}

The research place was "Comprehensive Research Laboratory of Tehran University of Medical Sciences". The sample size( the number of cells) required for culture in each test was selected using similar articles. The study was approved by the National Committee of Biological Research Ethics at Tehran University of Medical Sciences, Research and Technology Assistance. All methods were performed in accordance with the relevant guidelines and regulations.

\section{Cell line:}

The MCF7 cell line (DSMZ-German Collection of Microorganisms and Cell Cultures GmbH) culture, freeze, thaw, passage, and counting protocols were accomplished based on the ATCC method [17]. Based on the DSMZ legislation, the risk assessment is performed for every cell line $[18,19]$. Furthermore, we took constant vigilance and attention to good tissue culture practice and minimize the possibility of cross-contamination. We prevented mycoplasma, bacteria, fungi, and virus contamination. Phenotypic instability indicates cross-contamination [20]. We didn't face a change in MCF7 cell line behavior or morphology. The cell line cultured in complete culture 
medium; 90\% Dulbecco's modified Eagle's medium (DMEM)-High glucose (Gibco) supplemented with 10\% heatinactivated fetal bovine serum (FBS)(Gibco), $100 \mu \mathrm{g} / \mathrm{ml}$ streptomycin and $100 \mathrm{U} / \mathrm{ml}$ penicillin (PAN-biotech). Cancer cells were incubated at $37^{\circ} \mathrm{C}, 5 \% \mathrm{CO}_{2}$ in a sterile biosafety hood environment, and the medium was changed every 48 -hour. Cells grew up to $80-90 \%$ confluence and remained in the serum-free culture medium overnight. On the next day, senescence detached cells were removed and medium exchanged with DMEM-High glucose and $0.5 \%$ FBS for three hours (hrs). Therefore, growing cells were unified and synchronized in a similar logarithmic phase [21]. These uniform cells were utilized for the following experiments.

\section{Isolation, culture, and characterization of hUCMSCs:}

Fresh umbilical cords were received from three informed, consenting healthy mothers (in terms of diabetes, preeclampsia, hepatitis $B$, and AIDS). The umbilical cords were received after taking the informed consent from mothers at a general hospital in Tehran by institutional consent form of Tehran University of Medical Sciences. Based on Ranjbaran et al.[22] and Mennan et al.[23] protocols, under sterile conditions, $15-20 \mathrm{~cm}$ long pieces of umbilicus were submitted to the laboratory in a 50-ml falcon tube containing Hank's balanced salt solution (Sigma-Aldrich) supplemented with $100 \mu \mathrm{g} / \mathrm{ml}$ streptomycin and $100 \mathrm{U} / \mathrm{ml}$ penicillin within the optimal processing period of two hrs. Under the laminar flow hood, the sample was placed in a 15-cm petri dish (BIOFIL, China). The umbilicus was rinsed several times with sterile physiologic serum and phosphate-buffered saline (PBS) (Gibco) supplemented with penicillin and streptomycin to dispel any blood and debris. During the next steps, we prevented the sample from drying by pouring PBS. The washed cords were cut further into smaller 2-3 $\mathrm{cm}$ pieces and each smaller piece cut lengthwise by surgical scissors and forceps and its vessels (one vein and two arteries) were removed from the jelly. Then, Warton's jelly was chopped into 1-2 $\mathrm{mm}$ pieces with a scalpel blade. Jelly pieces were placed down enough distance from each other on the sterile plastic 3.5-cm Petri dishes coated with $0.1 \%$ collagen (Appendix 1 ). After five minutes $(\mathrm{min})$ in the air atmosphere, the pieces stuck to the bottom of the plate. Then $100 \mu \mathrm{l}$ warm culture $90 \%$ DMEM-Low glucose (Gibco) medium supplemented with 10\% FBS, $1 \%$ penicillin, and streptomycin were carefully poured on them in a way the pieces did not float in the medium. Petri dishes gently and without shaking were incubated at $37^{\circ} \mathrm{C}$ in $5 \% \mathrm{CO}_{2}$ and remained the same for up to three days. Every three days the culture medium was changed and the Petri dishes were observed under the inverted microscope for stem cell growth from Warton's jelly pieces into the surrounding culture medium. After the stem cells grew, two $\mathrm{ml}$ of fresh DMEM-Low glucose culture medium was poured on the slices of jelly, moved horizontally to separate the pieces, and gently removed. To match the results, we used the hUCMSCs of one of the donors for experiments. Confluent stem cells were sub-cultured into a new T-25 tissue culture flask (BectonDickinson) for further expansion. After three passages, the hUCMSCs were characterized by flow cytometry through CD90, CD73, CD105, CD34, CD45 surface markers.

\section{Osteogenic and adipogenic differentiation of hUCMSCs:}

The growing hUCMSCs at passage $3(\mathrm{P} 3)$ were seeded in 6 -well culture plates $\left(1 \times 10^{4}\right.$ cells $/ \mathrm{ml}$ per well) in the DMEM-Low glucose medium. After the well was full of cells ( $90 \%$ confluence, after 2 days) the medium was switched to osteogenic (DMEM-High glucose, supplemented with $2 \% \mathrm{FBS}, \beta$ Gglycerophosphate $(10 \mathrm{mg} / \mathrm{ml}$ ), Dexamethasone $(1 \mathrm{mg} / \mathrm{ml})$, L Ascorbic acid $(0.2 \mathrm{mmole})$ ) or adipogenic (DMEM-High glucose, supplemented with $2 \%$ FBS, Dexamethasone (100 nano mole), Indomethacin (50microg/ml), 3-Isobutyl-1-methylxanthine and Human recombinant insulin $(10 \mathrm{\mu g} / \mathrm{ml}))$ induction medium at $37^{\circ} \mathrm{C}$ in $5 \% \mathrm{CO}_{2}$ based on the Sigma aldrich protocol with slight modifications[24]. The medium was changed every three days with a new induction medium 
until 3 weeks. After washing with PBS, the cells were fixed with 4\% paraformaldehyde for 45 minutes. After removing the fixative, samples were incubated for 10 minutes with 1\% solution of Alizarin Red in a dark room or 15 minutes with $5 \%$ solution of Oil Red $O$ for osteogenic and adipogenic staining respectively. After draining the dye and washing 3 times with PBS, the results were observed and imaged with an inverted microscope.

\section{Conditioned media extraction:}

For the CM extraction(such as Mirabdollahi et al.[25] and Dzobo et al.[26] procedures), the early passages (P4P5) of hUCMSCs were grown up to $70 \%$ confluence in T-25 tissue culture flask, the medium was removed, hUCMSCs monolayers were washed once with PBS and the cells were then re-incubated with 5 ml new serumfree DMEM- High glucose medium. After 48 hrs, the medium was collected to a $15-\mathrm{ml}$ Falcon tube, centrifuged at $500 \mathrm{~g}$ for five min, the clear supernatant was separated, passed through a $0.22-\mu \mathrm{m}$ syringe filter (Millipore,Billerica, MA), aliquoted, and froze at- $20^{\circ} \mathrm{C}$ until further use. The $\mathrm{pH}$ and osmolality of the hUCMSCs$\mathrm{CM}$ were determined before use in all experiments. We used three concentrations of hUCMSCs-CM in treating groups:

1-Pure conditioned media extracted from hUCMSCs monolayers (CM100\%).

2-The conditioned media extracted from hUCMSCs monolayers diluted with an equal value of DMEM-High glucose (CM50\%).

3-The conditioned media extracted from hUCMSCs monolayers (50\%) in combination with an IC50 value of atorvastatin(CM+ATO).

The DMEM-High glucose contains $4500 \mathrm{mg} / \mathrm{L}$ dextrose [27]. To match the glucose concentration, we supplemented $4500 \mathrm{mg} / \mathrm{L}$ dextrose (Gibco) to CM100(CM100\%) and $2250 \mathrm{mg} / \mathrm{L}$ dextrose to CM50(CM50\% )and CM+ATO treated groups.

The MCF7 cell line cultured in DMEM-High glucose without any treatment was considered as control. Three replicates were employed for both treated and untreated groups.

\section{Atorvastatin:}

Atorvastatin Calcium salt powder $\left(\mathrm{C}_{66} \mathrm{H}_{68} \mathrm{Ca} \mathrm{F}_{2} \mathrm{~N}_{4} \mathrm{O}_{10}\right.$, Molecular weight: $1155.363 \mathrm{~g} / \mathrm{mole}$ ) (Sigma Aldrich) is a hydrophobic substance, dissolved in organic solvents such as Dimethyl sulfoxide (DMSO), Dimethylformamide (DMF), and ethanol $[28,29]$. These solvents themselves have shown a dose-dependent toxicity effect on MCF7 cells. If the maximum concentrations of ethanol and DMSO are $0.5 \%$ and DMF is $0.1 \%$, this underlying effect is significantly reduced[30]. DMSO (Beyotime, Shanghai, China) has the lowest final concentration (less than $0.1 \%$ in DMEM medium), thus we used the DMSO as the atorvastatin solvent. After making the drug to a stock concentration of 100 nano mole per milliliter $(\mathrm{nm} / \mathrm{ml})$ in PBS (1.155 mg ATO + $100 \mu \mathrm{l}$ DMSO + $9900 \mu \mathrm{l}$ PBS), ATO diluted with DMEM- High glucose medium to the final concentrations of $5,10,15,20,30,40,50$ (nm/ml) based on the M1V1=M2V2 equation.

\section{MTT assay:}


We utilized the MTTcolorimetric protocol to assay the mitochondrial respiration rate of viable cells with and without treatment [31,32]. The yellow MTT powder(3-(4,5-Dimethylthiazol-2-yl)-2,5-diphenyltetrazolium bromide) (Sigma-Aldrich) was dissolved in PBS at a final concentration of $0.5 \mathrm{mg} / \mathrm{ml}$. Exponentially MCF7 growing cells were seeded in 96 -well culture plates $\left(1 \times 10^{4}\right.$ cells $/ \mathrm{ml}$ per well) with $100 \mu$ l culture medium. The complete culture medium containing cells without any treatment were considered as control. Blank wells had medium and MTT without cells. Samples were treated with various concentrations of ATO, CM, and also CM+ATO, incubated for 1,2,3 days for ATO and 2 days for other groups' MTT assays. After the incubation time, we removed the medium, and $40 \mu \mathrm{l}$ MTT reagents were added to each well and left for three hrs in the incubator. After removing the MTT reagent, the colored Formazan product was dissolved in $200 \mu \mathrm{l}$ DMSO and plates were shaken for 20 min at room temperature for fully dissolving the MTT product. We measured the optical density (OD) of products at a maximum absorbance wavelength of $570 \mathrm{~nm}$ with an ELISA microplate reader (Bio-Rad Laboratories, Inc., Hercules, CA, USA). The relative MCF7 viability (\%) was calculated as follows:[(mean O.D of samples - mean O.D of blanks)/(mean O.D of controls-mean O. D of blanks)] $\times 100$.

After one day of incubation with various concentration of ATO, the half-maximal inhibitory concentration $\left(\mathrm{IC}_{50}\right.$ : The concentration of ATO $\left(\log _{10} \mathrm{x}\right)$ which reduces the cell viability by $50 \%$ of the upper asymptote) calculated by GraphPad Prism 6 software. The result was employed for subsequent proliferation and migration experiments.

\section{Apoptosis assay by flow cytometry:}

Annexin-V/PI double staining can discriminate necrotic, apoptotic, and viable cells population by flowcytometry. Annexin V-FITC/PI (Sigma-Aldrich kit, USA) was used according to the manufacturer's protocol. Equal numbers of MCF7 $\left(1 \times 10^{6}\right.$ cells $\left./ \mathrm{ml}\right)$ were seeded in each well of a six-well plates, allowed to attach, and synchronized. Cells were then cultured in the IC50 value of ATO, CM(100\%,50\%), and CM+ATO combination for 48 hrs. Untreated cells were considered as control groups. Each independent replication performed in triplicate. The cells harvested by trypsinization (Gibco, UK), were washed twice with precooled $\left(4^{\circ} \mathrm{C}\right) \mathrm{PBS}$, incubated with $5 \mu \mathrm{l}$ Annexin V-Fluorescein isothiocyanate for $15 \mathrm{~min}$, followed by incubation with $10 \mu$ Propidium lodide (PI) for 5 min in dark at room temperature. The number of viable/dead cells and DNA content (during a mitotic cell cycle) were measured by the BD Accuri ${ }^{\text {тм }} \mathrm{C} 6$ flow cytometer and analyzed with Flow-Jo(version7) software.

\section{Quantitative Real-time PCR:}

Quantitative real-time PCR method was employed to determine the mRNA level of apoptosis (Caspase $3,8,9)$ and anti-apoptosis (Bcl-2) genes after 48 hrs incubation with three different replicates of ATO, CM, and CM+ATO.

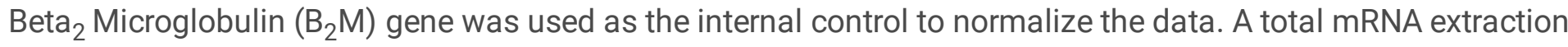
with Trizol (Invitrogen, USA) and cDNA synthesis with a cDNA synthesis kit (Takara, Japan) was performed according to the manufacturer's protocol. The primers were designed through the Primer3 software and synthesized by Takara Biotechnology (Japan)(Table1). The products were measured by ABI PRISM 7500 fast real-time sequence detection system (Applied Bio systems, Foster City, CA, USA). The PCR parameters were denaturation at $93^{\circ} \mathrm{C}$ for one min, annealing at $59^{\circ} \mathrm{C}$ for one min, and extension at $72^{\circ} \mathrm{C}$ for one min, for 40 cycles. Relative mRNA quantification was calculated based on the fold-change equation (fold change $=2^{-(\Delta \Delta C t)}$ ).

\section{Characterization of cell morphology:}


Following 48 hrs of incubation in 24-well plates, morphological characterization of treated and untreated MCF7 single cells was photographed with a reverse light microscope (TCM400-LABOMED) by Olympus software. DAPI (4',6-diamidino-2-phenylindole) fluorescent dye staining was used to study and analyze DNA changes due to apoptosis according to the instructions [33]. Morphological changes were viewed using fluorescence microscopy (Zeiss, Oberkochen, Germany) with Optika vision pro software .

\section{Hanging drop aggregation assay:}

Three-dimensional (3D) spheroid cell cultures imitate the natural cancer cell-cell and cell-micro environments interactions. Hence, the hanging drop assay is utilized as a simple 3D model to test anti-cancer therapy. Two ml of PBS was placed in the bottom of the six-well plate as a hydration chamber. The lid was inverted and 5000 cells in five $\mu$ l separated drops carefully deposited on the inner side of the lid by a $10 \mu$ l yellow pipette tips sufficiently apart not to touch each other (three drops in the lid of every chamber of the six-well plate). Five $\mu$ l of ATO, CM, CM+ATO, and the complete medium (as control) were added to drops. The lid gently was turned upside down and placed on top of the plate (Appendix2). Cells spontaneously aggregated at the tip of the drop and hang from the lid under the force of gravity, and gradually formed the spheroids. The clusters were photographed by an inverted microscope every other day. When the spheroids aggregated, their total size area were measured with ImageJ software.

\section{Scratch-wound healing assay:}

The scratch-wound assay is a simple, two-dimensional(2D), reproducible, common assay[34]. This in-vitro healing process surveys the migration speed in a sheet of cells responding to crude wound formation. In order to photograph from the same fixed point at different times, we marked the cross lines behind the bottom of wells before cell seeding (Appendix3). The intersection of two lines was compared as a fixed criterion. In each well, $5 \times 10^{5} \mathrm{cell} / \mathrm{s} / \mathrm{ml}$ were seeded into a 24 -well plate and cultured in a serum-free medium. Once the cells grew up to $90 \%$ confluence, the medium and cell debris were carefully aspirated. Then, we scratched a thin vertical wound line through the center on a monolayer cell culture, which got straight firmly and swiftly from top to bottom of the floor with a sterile yellow $200 \mu \mathrm{l}$ pipette tip and slowly washed detached cell debris with PBS once. One $\mathrm{ml}$ of ATO, CM, CM+ATO, and complete culture medium (as control) were added to each group. The first picture was immediately acquired with an inverted light microscope based on the intersection of two lines and the plate was incubated in an incubator. The speed of cell migration and wound closure was quantified by taking snapshot pictures at 3, 24, 48, 72-hour intervals from those fixed criterion point. We repeated this test more than 10 times to obtain comparable and reliable results. Pictures were analyzed with the Image J software and the relative wound healing area(\%)[(width of the wound after 3,24,48,72 hrs)(width of the wound in $\left.0 \mathrm{hr})^{-1} \times 100\right]$ was calculated.

\section{Trans-well migration assay:}

The trans-well migration assay measures the migration of cells(chemotaxis) toward a chemoattractant(chemical signal) in the three-dimensional cell's surrounding environment. According to the instruction [35] under the sterile biosafety hood in a 24 -insert well plate (pore:8 micron, Corning USA) $1 \times 10^{5}$ MCF7 cells $/ \mathrm{ml}$ in $100 \mu \mathrm{l}$ of the serum-free culture medium (in control group) or $100 \mu \mathrm{l}$ of the conditioned medium $(50 \%, 100 \%)$, atorvastatin or a combination of the conditioned medium and atorvastatin without serum (in the intervention 
groups) was poured on the above of the membrane in upper chambers. In the bottom of the lower chambers, 600 $\mu \mathrm{l}$ of the complete culture medium with serum was poured as a chemical adsorbent for cell migration. The bottom of the upper porous membrane made well contact with the chemo-attractant culture medium in the lower chamber to form a chemotactic gradient for the cells. Inside the sterile culture incubator, under standard conditions, MCF7 cancer cells with an average diameter of $18 \pm 2 \mu \mathrm{m}[36]$ crossed the porous membrane and invaded the underlying environment. Because MCF7 cells are adhesive, a number of migrating cells attached to the other side of the porous membrane. After 48 hours, the upper insert well was gently removed. The environment and the remaining cells inside the upper well were removed using a cotton swab applicator. This was repeated several times so that the non-migrating cell didn't remain in the upper well. The insert well was transferred to a new 24-well containing trypsin-EDTA and placed for 10 minutes to remove cells adhering to the underside of the membrane. Also, the cells that passed through the lower well were detached using trypsin-EDTA. After centrifugation, the number of cells in each intervention and control groups were counted under the hemocytometer(neobar) slide. Relative cell number (\%) was calculated as follows:(mean cell number of controls / mean cell number of samples× 100).

Because a number of dead cells also passed through the pores due to gravity and went to the lower chamber, to identify the living cells, we stained the lower chamber of one well in each group with DAPI.

\section{Statistical analysis:}

Data from control and experimental groups were analyzed employing IBM SPSS statistics (Version 22) software. Mean values \pm standard deviation (SD) were used to describe the data. Statistical comparisons between groups were measured with One-Way ANOVA and the post hoc multiple comparisons on the basis of Tukey's HSD test, Chi-Square test, Pearson Chi-Square test, Pearson Correlation test, and linear ANOVA regression test. The Pvalues of less than 0.05 were considered significant. Excel software (Microsoft office 2016) was used to draw the charts. Pictures were analyzed with the freely available ImageJ software(Appendix4).

\section{Results}

1.Morphological characterization and identification of hUCMSCs: After 14 days of primary explant culture, the fibroblast-like morphology and spindle-shaped plastic-adherent cells sprouted from Wharton's jelly pieces(Appendix5). They differentiated to adipocytes and osteocytes after 21 days. The surface CD markers were positive for CD73, CD105, and CD90 but negative for CD34 and CD45(Figure1). Thus the minimum criteria of MSCs [37] was affirmative. 2. CM+ATO inhibits the proliferation and induces the death of MCF7 in gross cell morphology: The treated and untreated MCF7 single cells were photographed after $48 \mathrm{hrs}$ incubation. Under normal conditions (control group) MCF7 cells grew up and proliferated to about $80 \%$ - $90 \%$ confluence in complete culture medium with spindle, multifaceted, and adhering to the bottom of a plastic flask. After 48 hours of contact with different concentrations of conditioned medium and atorvastatin, the proliferation of MCF7 cells reduced. In CM100 treated cells, the confluence appeared to be reduced to about 20\%, and in CM50 and CM50+ATO fetched up to about $40 \%$. While, the ATO scanty decreased the cells' proliferation, to about $70 \%$. Furthermore, the cancer cells became round small shrinkage and the nuclear chromatins were dark compressed and pyknotic, indicating apoptosis or necrosis in treated groups (Figure1-I). DAPI is a fluorescent dye that penetrates into living cells. As observed in Figure1-J, the control or untreated viable cells appeared to be intact regular normal nuclei were stained with bright blue fluorescence. Cells treated with CM or ATO decreased in 
proliferations and exhibited typical features of apoptosis such as cell shrinkage and chromatin condensation and fragmentation stained with dark blue fluorescence. Clearly, the morphological apoptotic observations showed significant alterations in CM+ATO treated cells. 3. MCF7 cells viability assay in ATO treated groups: Seven serial dilutions of ATO $(5 \mathrm{~nm} / \mathrm{ml}$ to $50 \mathrm{~nm} / \mathrm{ml})$ diminished the MCF7 cell viability after 24,48 and 72 hrs(Figure2-A). The more concentration of ATO, the less viability of MCF7 cells. Differences between mean relative viability of treated groups with different ATO concentrations were significant (One-Way ANOVA test sig $<0.05$ ). The Post Hoc Tukey HSD test represented that mean differences between $50 \mathrm{~nm} / \mathrm{ml}$ and control, $5 \mathrm{~nm} / \mathrm{ml}$ and $10 \mathrm{~nm} / \mathrm{ml}$ ATO were significant (Post Hoc Tukey HSD test sig <0.05). There was a correlation between MCF7 cell viability and ATO concentration (Pearson Correlation Sig. (2-tailed)<0.05). Also, there was linear regression between MCF7 cell viability and ATO concentration(ANOVA Regression Sig.<0.05), and the most coefficient of determination ( $R=0.979)$ was after $48 \mathrm{hrs}$ than $24 \mathrm{hrs}(\mathrm{R}=0.937)$ and $72 \mathrm{hrs}(\mathrm{R}=0.879)$. The ATO' IC50 value was calculated $18.41 \mathrm{~nm} / \mathrm{ml}$ after $24 \mathrm{hrs}$ exposure with the Graph Pad Prism6 software(Appendix6). Again, we utilized $18 \mathrm{~nm} / \mathrm{ml}$ ATO in further viability and migration tests. 4 . CM+ATO inhibits cell viability and promotes cell apoptosis in breast cancer cells: Pure (CM100) and diluted CM(CM50) conditioned medium, $18 \mathrm{~nm} / \mathrm{ml}$ ATO, and a combination of the $\mathrm{CM}(50 \%)$ and $\mathrm{ATO}(9 \mathrm{~nm} / \mathrm{ml})$ inhibited the MCF7 viability compared to the control group after 48 hrs in MTT assay(Figure2-B). The inhibitory effect of CM100(55\% viability, $45 \%$ inhibition) was more than twofold of CM50(89\% viability, $11 \%$ inhibition) and the outcome of ATO ( $64 \%$ viability, $36 \%$ inhibition) was between them. CM+ATO exhibited the most effect (34\% viability, $66 \%$ inhibition), interestingly, synergistic than the expected additive result $(36+11=47 \%$ inhibition). The differences between the mean relative viability of these five treated groups were significant (One-Way ANOVA test sig $<0.05$ ). The Post Hoc Tukey HSD test indicated that mean differences between CM+ATO treated group compared to the control and CM50 treated groups were significant. Besides, the difference between CM100 treated group and the control group was significant (Post Hoc Tukey HSD test sig $<0.05$ ). Annexin-V/PI double staining by flow cytometry assay revealed that after 48 hrs incubation, the cell density in the treated groups with conditioned medium (CM100, CM50, CM+AT0) were less than the control and the ATO treated groups, under similar conditions in the laboratory, due to the reduction in growth and proliferation in these groups (Figure3-A). The quadrant frequencies in control and treated groups were not equal (Chi-Square Asymp. Sig<0.05). The necrotic/late apoptotic (Q1) percentage in the CM+ATO treated group (14.3\%)revealed the synergic effect than CM50 and ATO solely $(11.8+0.947=12.747 \%)$ (Figure3-B). The viable (Q4 quadrant) cells decreased and necrotic and apoptotic (Q1+Q2+Q3 quadrants) increased after 48 hrs treatment, especially in CM100 and CM50 treated groups. The viable (Q4) and nonviable (Q1+Q2+Q3) quadrants frequencies in control and treated groups were not equal (Chi-Square Asymp. Sig<0.05). Furthermore, the differences between dead cell $(\mathrm{Q} 1+\mathrm{Q} 2+\mathrm{Q} 3)$ and living cell (Q4) quadrants in every treated group were significant in comparison with the control group (2-sided Exact sig in Pearson Chi-Square test $<0.05$ ) (Figure3-C). After $48 \mathrm{hrs}$, CM and ATO modified the mitotic cell cycle phases in malignant MCF7 cells. The mitotic cell cycle phases in control and treated groups were not equal (Chi-Square Asymp. Sig<0.05). The sub-G1 (apoptosis) phase in the control group was negative and increased up to $1 / 3$ following treatment with ATO and CM50(29.42\% and $33.97 \%$ respectively). Again CM+ATO synergistically elevated the apoptosis up to more than $2 / 3(69.32 \%$ ) of cell cycles(29.42+33.97=63.39\%)(Figure3-D). In addition, the sub-G1 phase and the sum of other phases $(G 1, S, G 2)$ frequencies differences between treated and control groups were significant(2-sided Exact sig in Pearson Chi-Square test<0.05) (Figure3-E). 5. The mRNA expression of apoptotic genes are upregulated in $\mathrm{CM}+\mathrm{ATO}$-treated breast cancer cells: Fold change mRNA expressions of apoptosis and anti-apoptosis genes in real-time PCR represented apoptosis enhancement over $48 \mathrm{hrs}($ Figure3-F). The caspase3, caspase8, and caspase 9 genes were up-regulated in treated cells, but Bcl-2 was down regulated. Differences between treated 
groups were significant (One-Way ANOVA test sig <0.05) compared to untreated cells. Most caspases 3, 8, 9 genes development and $\mathrm{Bcl}-2$ gene decrement were along with $\mathrm{CM}+\mathrm{ATO}$ treatment. Since the expression of 8 and 9 caspases genes increased, both of the extrinsic receptor-mediated and intrinsic mitochondrial-mediated apoptotic pathways are ascertained. The synergistic results of $\mathrm{CM}+\mathrm{ATO}$ treatment were explicit in the mRNA expression of apoptotic genes than Bcl2 (Table2). 6. CM+ATO inhibits the spheroid formation in MCF7 cancer cells: Spheroids aggregated in control groups after five days in the hanging drops. Two days later we analyzed and recorded the spheroids' total size area of different groups by ImageJ software (Figure4-A). Differences between treated groups compared to untreated groups were significant (One-Way ANOVA test sig <0.05)(Figure4B). Exposure of cancer cells to an $18 \mathrm{~nm} / \mathrm{ml}$ concentration of ATO detracted the spheroid total area(2.352$1.323=1.029 \%$ ). But the CM100 and the CM50 increased the spheroid total area up to( 9.002-2.352)6.65\% and (3.673-2.352)1.321\% respectively. It seems that CM disrupted the connections between cancer cells, and therefore the spherical shape of the tumor has lost its order and dispersed. This effect was more in CM100 group than CM50 group. However, in CM+ATO treated group, cancer cells were partially integrated together, which is due to the effect of ATO. In this group, due to higher cell death, cell proliferation was lower and the total mass size was smaller than the other CM intervention groups. The net expected increase of the area following the CM+ATO group (1.321-1.029=0.292\%) was lower than the observed value(1.555\%), confirms the stronger inhibitory effect of ATO on MCF7 spheroid formation 7. CM+ATO inhibits the breast cancer cells migration: Encounter with vertical and horizontal lines crossing under wells, we photographed the cellular migrations of the wound margins immediately and at intervals of $3,24,48$, and 72 hrs post scratching(Figure5-A). By adding MRI wound healing tool to ImageJ software, the relative wound healing surface area was adjusted and analyzed. Differences between treated groups compared to untreated groups were significant (One-Way ANOVA test sig $<0.05$ )(Figure5-B). In the control group, the wound closed after one day. But in treated groups, the wound was left open even after three days, because many cells didn't move and turned into necrosis or apoptosis. The wound closing delay with ATO lasted up to three days. On the other hand, the wound area overspread after three hrs exposure to $\mathrm{CM}(50 \%, 100 \%)$ and then irregularly retracted. After three days, the synergism effect of CM+ATO treating $(202.7 \%)$ on expected wound area $(104.01+26.02=130.03)$ explicitly was rather than former times. The number of cells attached to the lower side of the porous membrane and in the lower chamber of trans-wells decreased in treated groups after $48 \mathrm{hrs}$ incubation(Figure5-C). Relative cell number in treated groups were: 85\% in $\mathrm{CM} 100,51 \%$ in CM50,5\% in ATO, and 14\% in CM+ATO treated groups compared to control group. Differences between the mean \pm SD values in treated groups compared to untreated groups were significant (One-Way ANOVA test sig <0.05). In Figure5-D the fluorescence photographs samples of cell migrated staining with DAPI on the lower chamber of each group are shown. Untreated cells showed uniformly stained nuclei representing viable cells. While in CM and ATO treated groups chromatin condensation and DNA fragmentation appeared in a few migrated apoptotic cells.

\section{Discussion}

Hyperlipidemia is prevalent among women [38] and cholesterol represents a risk factor and impacts clinical outcomes of breast cancers[39]. The lipophilic ATO can easily penetrate cell membranes via passive diffusion. The cholesterol biosynthesis mevalonate (MVA) pathway is strictly regulated in normal cells, while the pathway deregulation promotes transformation [40]. Highly proliferating cancer cells generate lipid bi-layer membranes rapidly, increasing cholesterol biosynthesis [41]. The MVA pathway rate-limiting enzyme, 3-hydroxy-3-

methylglutaryl coenzyme A reductase (HMGCR) development is higher in estrogen-dependent mammary tumors

Page 10/27 
than healthy glands [42]. Thus, this molecule has been considered a new and special anti-cancer target. Statins inhibit the HMGCR enzyme, representing direct anti-cancer activity and multidrug resistance reversal ability in diverse cancers [43], and hinder cancer cell proliferation and survival [44]. For cancer patients already receiving statins for other situations, such as hypercholesterolemia, ATO may provide a pleiotropic anti-tumor advantage without adversely affecting their primary indication for statin therapy.

Morphological qualitative hallmarks of the terminal stages of apoptosis are chromatin condensation and genomic DNA fragmentation identified by DNA-binding nuclear dyes such as DAPI in fluorescence microscopy[45]. We illustrated significant apoptotic changes in morphological characterization of MCF7 single cells and nucleus staining especially in the CM+ATO treated group. Shrinkage of the cells, chromatin condensation, and formation of apoptotic bodies

in morphological features of cells, observed by Gauthaman et al. [12]. They also reported membrane blebbing and vacuolations and Gauthaman et al. encountered a decrease in cancer cell numbers after 72 hrs treatment with $\mathrm{CM}$.

In this investigation, results confirmed that ATO decreases breast cancer MCF7 cell viability and movement in a dose- and time-dependent manner. Within the concentration range of 5 to $50(\mathrm{~nm} / \mathrm{ml})$, we found $0.16-61(\%)$ viability inhibition after $48 \mathrm{hrs}$, but Mueck et al. [46] obtained wider resultants (10-90\%) with 1.6-50 $\mu \mathrm{m}$ concentrations. The difference would be related to longer incubation (four days) or distinct cell proliferation test (ATP-chemo sensitivity). After three days the inhibitory effect of ATO was more significant than former days in our results and in Al-khafaji's research [47]. In Martinez et al.'s investigation, the inhibition effects of $5 \mu \mathrm{m}$ to 80 $\mu \mathrm{m}$ concentrations of ATO were statistically significant at $48 \mathrm{hrs}$, but after $24 \mathrm{hrs}$ only 40 and $80 \mu \mathrm{m}$ of ATO exhibited significant effects [48]. In other research [49] MCF7 cells were less sensitive to ATO, requiring doses more than $20 \mu \mathrm{m}$ to carry out the proliferation rates under $30 \%$ after $72 \mathrm{hrs}$. Nevertheless, in a $10 \mu \mathrm{m}$ concentration of ATO, a significant decrease was observed in the survival of MCF7 cells after 24, 48, and 72 hrs compared to control cells in Shahrokhabadi et al.'s study [50]. The survival of MCF7 cells did not change by $5 \mu \mathrm{m}$ ATO after 72 hrs exposure [51]. Clearly, Shahrokhabadi et al. [50] did not prove statistical significance in the cytotoxicity effect of lower concentrations $(0.1$ to $1 \mu \mathrm{m})$. The IC50 value in our estimation was $18 \mathrm{~nm} / \mathrm{ml}$ following 24 hrs exposure to ATO. However, others measured further [52,53,54] or lesser $[47,55]$ values of ATO. The diversities could be the result of different drug manufacturers, drug solvent, cell culture medium, viability examination, and the time point for figure out the IC50 of ATO.

We resulted that the CM100 has been shown more inhibitory effect than ATO and CM50, while the CM+ATO combination has the most, synergistic effect. More importantly, the concentration of the ATO in this combination was also halved ( $9 \mathrm{~nm} / \mathrm{ml}$ in CM+ATO), but its effect increased along with the conditioned medium. Likewise, Mirabdollahi et al. found that human Wharton's jelly mesenchymal stem cells-derived secretome can inhibit the growth of MCF7 cell lines in vitro and in vivo. The IC50 was determined as $\geq 10 \mathrm{mg} / \mathrm{ml}$ [25]. Gauthaman et al. showed that MDA-MB-231breast cancer proliferation was significantly inhibited by CM in MTT assay [12]. The outcome of CM50 (16.39\%) was more than our result (11.12\%), while the effect of CM100(22.96\%) was lesser than our consequence (46.7\%). The difference can be related to another cell line or upper passages (P3-P7) in Gauthaman et al.'s study. Dzobo et al. deduced that Wharton's jelly-derived mesenchymal stromal cells CM and fibroblast-derived extracellular matrix synergistically inhibit MDA MB 231 cell proliferation after co-culturing for $72 \mathrm{hrs}$ than individually through apoptosis [26]. As well as, direct co-culture of hUCMSCs for $48 \mathrm{hrs}$ inhibited the 
growth of MDA-MB-231[56,13] and MCF7 in a dose-dependent manner [13]. In Li et al.'s study[14], CM from 10 and 20\% hUCMSCs, significantly promoted the proliferation of MCF7 and MDA-MB-231 in vitro.

Quantitative detection of condensed apoptotic nuclei can be identified by flow cytometry. We have demonstrated that After 48 hrs of treatment with CM $(100 \%, 50 \%)$ and ATO, more than half of Annexin-V / PI stained particles were early and late apoptotic and necrotic cells (Q1+Q2+Q3 quadrants), while in CM+ATO group incremented up to $38 \%$. ATO significantly increased the early apoptosis (Q3 quadrant) cells and CM(100 and 50\%) augmented the necrotic (Q2 quadrant) cells. But the momentous result of CM+ATO synergism was represented in necrotic/late apoptotic(Q1 quadrant)percentage. Mayson et al. reported only $5.67 \%$ early apoptotic and $4.23 \%$ late apoptotic cells with ATO [57]. This low quantity could be owing to a lower concentration of ATO $(5 \mu \mathrm{m})$ compared to our study. The TUNEL assay also exhibited the concentration-dependent apoptotic enhancement of MCF7 cells after 10, 20, and $80 \mu \mathrm{m}$ treatments with ATO in Martinez's study [48].

In our research an increase in the percentage of cells stalled at sub-G1 in all of the treated groups and G2 phases in the CM50 group declared the apoptosis and metaphase arrest similar to Gauthaman's [12] for the MDA-MB231 cell line. The increment of Zalatnai et al. [59] concluded that "apoptosis is more frequent in arrested cells in the $\mathrm{G} 1$ phase whereas necrosis is more frequent in cells arrested in the G2/M phase". In Sanchez et al.'s study[54], the ATO' IC50 $40 \mu \mathrm{m}$ within 48 hrs significantly increased the number of cells in the G2/M and G1phases based on two different staining methods compared to the non-statin treated cells. Direct hUCMSCs cocultured with MDA-MB-231 breast cancer stem cells also increased the number of apoptotic and necrotic cells [13]. Dzobo et al. [26] and Ayuzawa et al. [60] also showed G2 populations increasing in MDA 231 cells by hUCMSCs. Even though, in Ayuzawa's research, small amounts of co-cultured hUCMSC or its conditioned medium inhibited DNA synthesis.

Mück et al. [61]and Gauthaman et al. [12] reported down-regulation of the anti-apoptotic protein Bcl-2 resulted from ATO and human Wharton's jelly stem cell extracts on breast cancer cells respectively. Decreasing in antiapoptotic gene Bcl-2 in Gauthaman et al.'s study(9.8-fold) was notably further than our result( 0.61 -fold). Besides, Gauthaman et al. suggested that inhibition of MDA-MB-231 cell growth was via autophagy. Dzobo et al. [26] reported the activation of caspases 3and 9 and another apoptotic gene (p21-p53in G2 phase cell cycle arrest) up regulation and anti-apoptotic genes (Bcl-2, Bcl-xL, and cyclin D1) down regulation by human $\mathrm{CM}$. Ayuzawa et al. [60] showed a slightly increased caspase 3 substrate PARP cleavage.

Clonal formation inhibited by ATO ( $4 \mu \mathrm{M}$ for MDA-MB-231,2 $\mu \mathrm{M}$ for MCF7) in a 6-well plate 2D culture after one week in Ma et al.'s [58]. The effects of statins would be through the combination of factors such as increased death, reduced growth, and reduced invasion. In Li et al.'s study [14] CM (10 and 20\%) significantly increased the plate clone formation rates after 10 days. A similar total area increasing was done in our result, but spheroids lost their sharp configurations.

Direct hUCMSCs co-culturing significantly reduced the number of breast cancer stem cell colonies at the bottom of the soft agar [13]. In Ayuzawa et al.'s study after 10 days, the attenuation in the colony formation of MDA 231 seeded on top of the bottom agar layer due without direct contact to naive hUCMSCs placed under the bottom agar layer, confirmed the effect of diffusible mediators [60].

We showed that all treatments decreased the wound closing rate. Hence, MCF7 cells lost their regular oriented movement, and the wound overspread until one day and then retracted. Even though, CM and CM+ATO 
disintegrate cell relations as it was shown in the hanging drop test.

In the scratch-wound healing assay, after one day, the wound area increasing could be the result of decreasing cell viability. Although, in Li's study [14] the CM (10\% and significantly with $20 \%)$ increased the wound closure ratios of MCF7 and MDA-MB-231 cancer cells after $24 \mathrm{hrs.}$

In Mi et al.'s research [62], $10 \mu \mathrm{m}$ ATO treatment did not affect the migration of MCF7 cells. Surprisingly Li et al. [14] showed that CM (10 and 20\%) promoted the proliferation and migration of MCF7 and MDA-MB-231 breast cancer cell lines. Li et al. speculated that their contrary results to those other studies may be related to the type and site of the carcinoma, differences in the culture and experimental methods, the numbers and sources of the MSCs, or a combination of these elements.

In this research, for the first time, we investigated the effect of ATO and CM on a cancer cell's growth and migration. Even though, the synergistic effect of statins and high concentration of hUCMSCs-derived secretome (20\%) MSC in enhancing migration and proliferation of non-cancerous endothelial progenitor cells have been studied in Oktaviono et al.'s study [16]. Besides, in a rabbit model of acute myocardial infarction, ATO improved the microenvironment to enhance the beneficial effects of bone marrow-derived mesenchymal stromal cells therapy [15].

The tumor microenvironment contains an extracellular substrate, different cell types, and secreted growth factors and metabolites. Mesenchymal stromal cells are part of the tumor stroma and may have conflicting effects on tumor growth and progression. The $\mathrm{CM}$ is containing different growth factors, chemokines, cytokines, and different interfering RNAs such as micro-RNAs. Better understanding of crosstalk between hUCMSCs and breast tumor cells will be able to develop potential strategies in the treatment of tumors in the future. Since the chronic, low doses administration of chemotherapeutic drugs can diminish or eliminate tumors, it is quite possible that the conditioned medium derived from hUCMSCs and estrogen lowering agents behave similarly to chemotherapeutic drugs.

In this study, due to some limitations (including the COVID-19 epidemic), we could not examine the signaling pathways of this synergistic effect. But this idea can help researchers in future studies.

\section{Conclusions}

Based on our knowledge, the present study is the first to demonstrate that human umbilical cord matrix-derived mesenchymal stem cells-conditioned medium and atorvastatin combination synergistically diminishes proliferation and migration of human mammary carcinoma cells in vitro. Various methods such as the MTT, Annexin V/PI flow cytometry, real-time PCR, morphological changes, hanging drop aggregation, scratch-wound healing, and trans-well migration assay revealed the importance of the extracellular space for enhancing the efficacy of therapeutic agents. In summary, the results might actuate the evolvement of novel adjuvant anticancer therapeutics based on targeting or modifying the ECM to increase chemotherapy toxic results or to prevent metastatic colonization.

\section{Abbreviations}


Synergism effect: Synergism comes from the Greek word "synergos" meaning working together. The synergism refers to the effect caused when exposure to two or more chemicals at one time results in health effects that are greater than the simple summation of the effects of the individual chemicals.

MCF7:Michigan Cancer Foundation-7

MSCs: Mesenchymal stem cells

hUCMSCs: Human umbilical cord matrix derived mesenchymal stem cells

CM: Human umbilical cord matrix derived mesenchymal stem cells-conditioned medium

ATO: Atorvastatin

CM100: Pure conditioned media extracted from hUCMSCs monolayers (CM100\%).

CM50: The conditioned media extracted from hUCMSCs monolayers diluted with an equal value of DMEM-High glucose (CM50\%).

CM+ATO: Human umbilical cord matrix derived mesenchymal stem cells-conditioned medium (50\%) and atorvastatin combination $(9 \mathrm{~nm} / \mathrm{ml})$

HR: Hormone (estrogen or progesterone) receptors

HER2: Human epidermal growth factor receptor 2 gene

DMEM: Dulbecco's modified Eagle's medium

FBS: Fetal bovine serum

PBS: Phosphate-buffered saline

DMSO: Dimethyl sulfoxide

DMF: Dimethylformamide

MTT:3-(4,5-Dimethylthiazol-2-yl)-2,5-diphenyltetrazolium bromide

$\mathrm{IC}_{50 \text { : }}$ The half-maximal inhibitory concentration

HMGCR: 3-hydroxy-3-methylglutaryl coenzyme A reductase

MVA: Mevalonate

OD: Optical density

PI: Propidium lodide

3D: Three-dimensional 
2D: Two-dimensional

$\mathrm{nm} / \mathrm{ml}$ : Nano mole per milliliter

$\mu \mathrm{g} / \mathrm{ml}$ : Microgram per milliliter

$\mu \mathrm{m}$ : Micro mole

ml: Milliliter

mmole: Milli mole

hrs: Hours

min: Minutes

P: Passage

\section{Declarations}

\section{Acknowledgments:}

The authors extend their respects to Dr. Roya Karimi, Dr.Alireza Jalali, Dr.Abbas Ebadi, Dr.Mahdi Saberi, Dr. Mahdieh Hasanalifard, Dr. Masoomeh Saeedi, The Computer Engineer. Mohammad Abolghasemi, M.A Researching Saideh Abolghasemi, Midwife. Saeedeh Akhtari and Mr. Baharloui who friendly helped in finalizing this project. The authorswould like to express special thanks of gratitude to co-workers in"The Core Facility laboratory of Tehran University of Medical Sciences" and thanks to guidance and advice from the "Clinical Research Development Unit of Baqiyatallah Hospital".

\section{Funding:}

This study was supported by the foundation of Tehran university of medical sciences for Ph.D. thesis of applied cell sciences(Grant number:96-04-87-37248).

\section{Competing interests:}

The authors have no conflicts of interest to declare.

\section{Ethics approval:}

The experiment was approved by the National Committee of Biological Research Ethics at Tehran University of Medical Sciences, Research and Technology Assistance (Ethical Code: IR. TUMS. VCR. REC.1397.444). The authors confirm that any experimental and research methods reported in this paper were based on mandatory health and safety protocols in the laboratory procedures.

\section{Consent to participate:}

The umbilical cords were received after taking the informed consent from mothers at a general hospital in Tehran by "Institutional Consent Rorm of Tehran University of Medical Sciences”. 
Consent for publication:

All authors consent to the publication of the manuscript in the "Stem Cell Reviews and Reports" journal.

Availability of data and materials:

All data generated or analyzed during this study are included in this published article.

Code availability: Not applicable.

Authors' contributions:

Professor Jafar Ai is the main thesis manager. He created the main conception and design of the work. Dr. Somayeh Ebrahimi-barough is the second thesis manager. She revised and approved the manuscript. Dr.Reyhaneh Abolghasemi is a major contributor in writing the manuscript for Ph.D. thesis of applied cell sciences. All authors read and approved the final manuscript.

\section{References}

[1] Ferlay J, Soerjomataram I, Dikshit R, et al. (2015).Cancer incidence and mortality worldwide: sources, methods and major patterns in GLOBOCAN 2012. Int J Cancer, 136, E3,59-86.

[2] Breast Cancer Facts \& Figures 2017-2018. American Cancer Society, Inc. Williams Street, NW, Atlanta, GA 30303-1002 404-320-3333.2019.

[3] Mbeunkui F, Johann DJ Jr. (2009). Cancer and the tumor microenvironment: A review of an essential relationship. Cancer Chemother Pharmacol,63: 571-82.

[4] Whiteside TL. (2008). The tumor microenvironment and its role in promoting tumor growth. Oncogene,27: 5904-12.

[5] Deborah L H, Valerie S. (2011).Choosing the right cell line for breast cancer research. Breast Cancer Research, 13(215):7 pages.

[6] Mc Menamin ÚC, Murray LJ, Hughes CM, et al. (2016). Statin use and breast cancer survival: a nationwide cohort study in Scotland. BMC Cancer, doi:10.1186/s12885-016-2651-0.

[7] Rezano A, Ridhayanti F, Rangkuti AR, et al. (2020). Cytotoxicity of Simvastatin in Human Breast Cancer MCF-7 and MDA-MB-231 Cell Lines. Asian Pacific Journal of Cancer Prevention, doi:10.22034/APJCP.

[8] Hu MB, Zhang JW, Gao JB, et al. (2018). Atorvastatin induces autophagy in MDA-MB-231 breast cancer cells. Ultrastructural Pathology, doi:10.1080/01913123.2018. 1522406.

[9] Subramanian A, Shu-Uin G, Kae-Siang N, et al. (2012). Human Umbilical Cord Wharton's Jelly Mesenchymal Stem Cells Do Not Transform to Tumor-Associated Fibroblasts in the Presence of Breast and Ovarian Cancer Cells, Unlike Bone Marrow Mesenchymal Stem Cells. Journal of Cellular Biochemistry, 113:1886-95. 
[10] Wang HS, Hung SC, Peng ST, et al. (2004). Mesenchymal stem cells in the Wharton's jelly of the human umbilical cord. Stem Cells, 22:1330-37.

[11] Sarugaser R, Lickorish D, Baksh D, et al. (2004). Human umbilical cord perivascular (HUCPV) cells: a source of mesenchymal progenitors. Stem Cells, 23:220-29.

[12] Gauthaman K, Yee FC, Cheyyatraivendran S, et al. (2012). Human Umbilical Cord Wharton's Jelly Stem Cell (hWJSC) Extracts Inhibit Cancer Cell Growth in Vitro. Journal of Cellular Biochemistry, 113:2027-39.

[13] Ma Y, Hao X, Zhang S, et al. (2012). The in vitro and in vivo effects of human umbilical cord mesenchymal stem cells on the growth of breast cancer cells. Breast Cancer Res Treat, doi: 10.1007/s10549-011-1774-X.

[14] Li T, Zhang C, DingY, et al. (2015). Umbilical cord-derived mesenchymal stem cells promote proliferation and migration in MCF-7 and MDA-MB-231breast cancer cells through activation of the ERK pathway. ONCOLOGY REPORTS, doi: 10.3892/or.2015.4109.

[15] Qu Z, Xu H, Tian Y, et al. (2013). Atorvastatin Improves Microenvironment to Enhance the Beneficial Effects of BMSCs Therapy in a Rabbit Model of Acute Myocardial Infarction. Cell Physiol Biochem, doi:

$10.1159 / 000354445$.

[16] Oktaviono YH, Hutomo SA, Al-Farabi MJ, et al. (2020). Human umbilical cord blood-mesenchymal stem cellderived secretome in combination with atorvastatin enhances endothelial progenitor cells proliferation and migration. F1000 Research, doi:org/ 10.12688/f1000research.23547.1.

[17] ATCC Credible leads to Incredible,(2019). [online] Available at: https://www.atcc.org/products/all/HTB-22. Aspx \#culture method. [Accessed 26 October 2019].

[18] DSMZ collection. Safety Information, (2021). [online] Available at:

Https://www.dsmz.de/collection/catalogue/human-and-animal-cell-lines/safety-information. [Accessed 26 February 2021].

[19]Mcf-7, ACC 115. data sheet,(2021). [online] Available at:https://www.dsmz.de/collection/catalogue/details/culture/acc-115. [Accessed 26 February 2021].

[20] Section 4. Cell line problems: identification and elimination,(2021). [online] Available at:Https://cellbank.nibiohn.go. jp/legacy/information/guidelines/ukcccr/cell_linessec4.html. [Accessed 26 February 2021].

[21] Langan TJ, Chou RC. (2011).Synchronization of mammalian cell cultures by serum deprivation. Methods Mol Biol,761:75-83.

[22] Ranjbaran H, Abediankenari S, Mohammadi M, et al. (2018).Wharton's Jelly Derived-Mesenchymal Stem Cells:Isolation and Characterization. Acta Medica Iranica,56(1): 6 pages.

[23] Claire Mennan, Karina Wright, Atanu Bhattacharjee, et al. (2013). Isolation and Characterisation of Mesenchymal Stem Cells from Different Regions of the Human Umbilical Cord. BioMed Research International, doi:10.1155/2013/916136. 
[24] Trilineage Differentiation of Multipotent Human Mesenchymal Stem Cells (MSCs) into Osteocytes, Adipocytes and Chondrocytes. (2021). [online] Available at:https://www.sigmaaldrich.com/technicaldocuments/protocols/biology/cell-culture/mesenchymal-stem-cell-differentiation.html. [Accessed 20 April 2021].

[25] Mirabdollahi M, HaghjooyJavanmard SH, Sadeghi-aliabadi H. (2019). An anticancer effect of umbilical cordderived mesenchymal stem cell secretome on the breast cancer cell line. Cell Tissue Bank, doi:10.1007/s10561019-09781-8.

[26] Dzobo K, Vogelsang M, Thomford NE, et al. (2016). Wharton's Jelly-Derived Mesenchymal Stromal Cells and Fibroblast-Derived Extracellular Matrix Synergistically Activate Apoptosis in a p21-Dependent Mechanism in WHCO1 and MDA MB 231 Cancer Cells in Vitro. Hindawi Publishing Corporation Stem Cells International, doi:org/10.1155/2016/4842134.

[27] Sigma-Aldrich. Product Information. Dulbecco's Modified Eagle's Medium-low glucose. (2021). [online] Available at:https://www.sigmaaldrich.com/catalog/search?

term=dmem\&interface=All\&N=0+4294407710\&mode=match\%20partialmax\&lang=en\&region=IR\&focus=product. [Accessed 26 February 2021].

[28] U.S. National Library of Medicine. Atorvastatin calcium.(2019). [online] Available at:https://pubchem.ncbi.nlm.nih. gov/compound/atorvastatin_calcium. [Accessed 26 October 2019].

[29] Product information. Atorvastatin(calcium salt).item number10493.cayman chemical company. August5,2018.

[30] Leila Jamalzadeh, Hosein Ghafoori, Reyhaneh Sariri, et al (2016). Cytotoxic Effects of Some Common Organic Solvents on MCF-7, RAW-264.7 and Human Umbilical Vein Endothelial Cells. Avicenna J Med Biochem, doi: $10.17795 /$ ajmb-33453.

[31] Riss T L, Moravec R A, Niles A L, et al. Cell Viability Assays. Assay Guidance Manual. (2020) [online] Available at: https://www.ncbi.nlm.nih.gov/books/ NBK144065/?report=reader. [Accessed 3 September 2020].

[32] MTT Cell Proliferation Assay Instruction Guide. American Type Culture Collection. ATCC® 30-1010K. 2011.

[33] Sigma Aldrich. DAPI.(2021). [online] Available at:https://www.sigmaaldrich.com/catalog/product/sigma. [Accessed 20 April 2021].

[34] Justus C R, Leffler N, Echevarria M R, et al. (2014). In vitro Cell Migration and Invasion Assays. Journal of Visualized Experiments, doi:10.3791/51046.

[35] Calvin R. Justus,Nancy Leffler,Maria Ruiz-Echevarria,et al. (2014). In vitro Cell Migration and Invasion Assays. J Vis Exp, doi: 10.3791/51046.

[36] scientific reports.(2021) [online] Available at: https://www.nature.com/articles/srep14272/figures/3. [Accessed 20 April 2021].

[37] Lv FJ, Tuan RS, Cheung KMC, et al. (2014). Concise Review: The Surface Markers and Identity of Human Mesenchymal Stem Cells. Stem Cells,32:1408-1419. 
[38] Phan BAP, Toth PP. (2014). Dyslipidemia in women: etiology and management. Int J Womens Health, doi: $10.2147 /$ IJWH.S38133.

[39] Laverias G, Danilo C, Mercier I, et al. (2011). Role of Cholesterol in the Development and Progression of Breast Cancer. The American Journal of Pathology, doi: 10.1016/j.ajpath.2010.11.005.

[40] Pandyra AA, Mullen PJ, Goard CA, et al. (2015). Genome-wide RNAi analysis reveals that simultaneous inhibition of specific mevalonate pathway genes potentiates tumor cell death. Oncotarget, 6: 26909-21.

[41] Mullen PJ, Yu R, Longo J, et al. (2016) The interplay between cell signaling and the mevalonate pathway in cancer. Nat Rev Cancer, 16: 718-31.

[42] El-Sohemy A, Archer MC. (2000). Inhibition of N-methyl-N-nitrosourea- and 7,12-dimethylbenz[a] anthraceneinduced rat mammary tumorigenesis by dietary cholesterol is independent of Ha-Ras mutations. Carcinogenesis, 21: 827-31.

[43] Steven G. (2004). Reducing cholesterol and overcoming drug resistance. Blood,104(6):1598-99.

[44] Campbell MJ, Esserman LJ, Zhou Y, et al. (2006). Breast cancer growth prevention by statins. Cancer Res, 66: 8707- 14.

[45] abcam. Nuclear condensation, DNA fragmentation and membrane disruption during apoptosis. (2021) [online] Available at:https://www.abcam.com/kits/nuclear-condensation-dna-fragmentation-and-membranedisruption-during-apoptosis. [Accessed 20 April 2021].

[46] Mueck AO, Seeger H, Wallwiener D. (2003). Effect of statins combined with estradiol on the proliferation of human receptor-positive and receptor-negative breast cancer cells. Menopause: The Journal of the North American Menopause Society, doi: 10.1097/01. GME.0000055485.06076.00.

[47] Al-khafaji AHY, Arif IS. (2018). Evaluation of anti-proliferative activity of simvastatin and atorvastatin on MCF7 cell line compared with doxorubicin using MTT test. AJPS, doi: org/10.32947/ajps.18.02.0386.

[48] Martinez TA, Zeybek ND, Müftüoğlu S. (2018). Evaluation of the Cytotoxic and Autophagic Effects of Atorvastatin on MCF-7 Breast Cancer Cells. Balkan Med J, doi: 10.4274/balkanmedj.2017.0604.

[49] Kimbung S, Lettiero B, Feldt M, et al. (2016). High expression of cholesterol biosynthesis genes is associated with resistance to statin treatment and inferior survival in breast cancer. Oncotarget,7(37): 59640-51.

[50] Shahrokhabadi KH, Baharara J, Zafar balanejad S, et al. (2014). The effect of atorvastatin on progress and proliferation of mcf7 breast cancer cell line. Journal of advances in medical and biomedical research, 21(88):11pages.

[51] Beckwitt CH. (2018). Breast cancer metastatic dormancy and emergence, a role for adjuvant statin therapy. Dissertation. University of Pittsburgh.

[52] Beckwitt C H, Shiraha K, Wells A. (2018). Lipophilic statins limit cancer cell growth and survival, via involvement of Akt signaling. PLOS ONE, 15:22pages. 
[53] H. Seeger, D. Wallwiener, A. O. Mueck. (2003). Statins Can Inhibit Proliferation of Human Breast Cancer Cells in Vitro. Exp Clin Endocrinol Diabetes, doi: 10.1055/s-2003-37501.

[54] S'anchez CA, Rodr'ıguez E, Varela E, et al. (2008). Statin-Induced Inhibition of MCF-7 Breast Cancer Cell Proliferation is Related to Cell Cycle Arrest and Apoptotic and Necrotic Cell Death Mediated by an Enhanced Oxidative Stress. Cancer Investigation, doi: 10.1080/07357900701874658.

[55] George M. Mekhail, Amany O. Kamel, Gehanne A.S. et al. (2012). Anticancer effect of atorvastatin nanostructured polymeric micelles based on stearyl-grafted chitosan. International Journal of Biological Macromolecules, 51:351-63.

[56] Chao KC, Yang HT, Chen MW. (2012). Human umbilical cord mesenchymal stem cells suppress breast cancer tumourigenesis through direct cell-cell contact and internalization. J. Cell. Mol. Med, doi:10.1111/j.15824934.2011.01459. $x$.

[57] Alkhaitb M H, Al-Saedi DA. (2017). Cytotoxic Effect of the Combination of Gemcitabine and Atorvastatin Loaded in Nanoparticle on the MCF-7 Breast Cancer Cells and HFS

Human Foreskin Cells. Current Nanoscience, 13: 625-33.

[58] Ma Q, Gao Y, Xu P, et al. (2019). Atorvastatin Inhibits Breast Cancer Cells by Downregulating PTEN/AKT Pathway via Promoting Ras Homolog Family Member B (RhoB). Bio Med Research International, doi: 10.1155/2019/3235021.

[59] Zalatnai, A. (2005). Potential Role of Cell Cycle Synchronizing Agents in Combination Treatment Modalities of Malignant Tumors. In Vivo, 19: 85-91.

[60] Ayuzawa R, Doi C, Rachakatla RS, et al. (2009). Naïve human umbilical cord matrix derived stem cells significantly attenuate growth of human breast cancer cells in vitro and in vivo. Cancer Letters, doi: 10.1016/j.canlet.02.011.

[61] Mück A.O, Seeger H, Wall wiener D. (2004). Inhibitory effect of statins on the proliferation of human breast cancer cells. Int Journal of Clinical Pharmacology and Therapeutics,42(12):695-700.

[62] Mi W, Lin Q, Childress C, et al. (2015). Geranylgeranylation signals to the Hippo pathway for breast cancer cell proliferation and migration. Oncogene, 34: 3095-3106.

\section{Tables}

Table1. Primer sequences used for Real time-PCR 


\begin{tabular}{|llll|}
\hline Genes & Size(bp) & Forward primer sequence(5'à3') & Reverse primer sequence \\
\hline Caspase3 & 143 & CAGTGGAGGCCGACTTCTTG & TGGCACAAAGCGACTGGAT \\
Caspase8 & 161 & GGATGGCCACTGTGAATAACTG & TCGAGGACATCGCTCTCTCA \\
\hline Caspase9 & 150 & TGTCCTACTCTACTTTCCCAGGTTTT & GTGAGCCCACTGCTCAAAGAT \\
BCL2 & 156 & CTT TTG CTG TGG GGT TTT GT & GTC ATT CTG GCC TCT CTT GC \\
B2M & 147 & TACATGTCTCGATCCCACTTAACTAT & AGCGTACTCCAAAGATTCAGGTT \\
\hline
\end{tabular}

Table2. The synergistic results of CM+ATO treatment fold change mRNA expressions of apoptosis and antiapoptosis genes

\begin{tabular}{|lllll|}
\hline Treatment groups & Casp3 & Casp8 & Casp9 & Bcl2 \\
\hline Control & 1 & 1 & 1 & 1 \\
\hline CM50 & 1.62 & 1.32 & 1.74 & 0.61 \\
\hline ATO & 2.64 & 2.14 & 3.48 & 0.81 \\
\hline CM+ATO Expected effect & $0.62+1.64=2.26$ & $0.32+1.14=1.46$ & $0.74+2.48=3.22$ & $1-(0.39+0.19)=0.42$ \\
\hline CM+ATO Synergism result & 3.03 & 2.14 & 4 & 0.53 \\
\hline
\end{tabular}

\section{Figures}




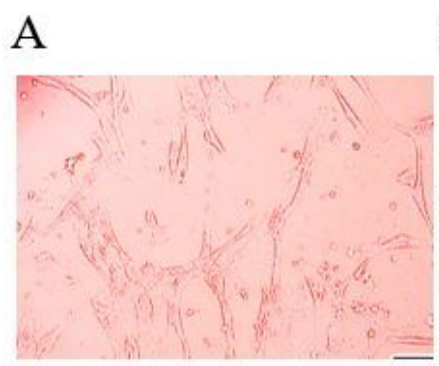

D

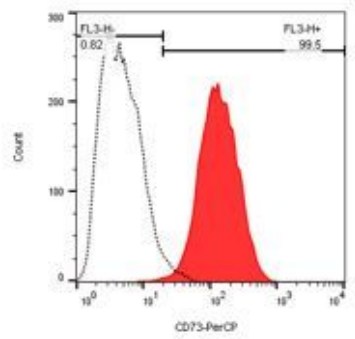

\section{Control}

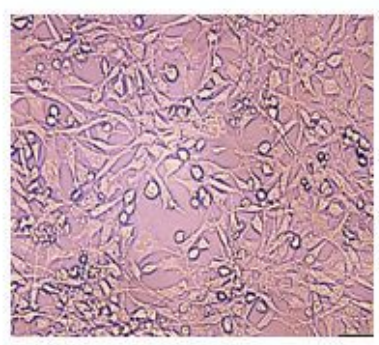

J

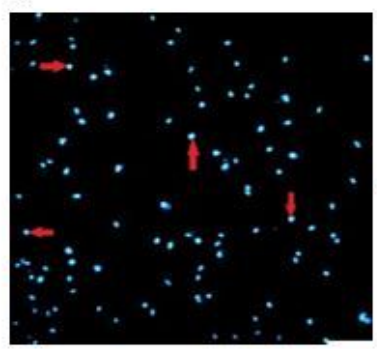

B

E

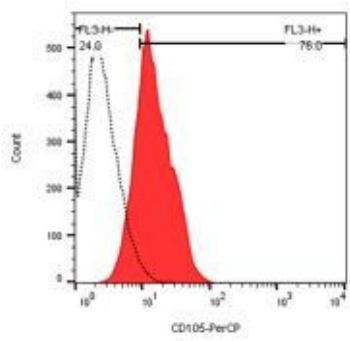

CM100
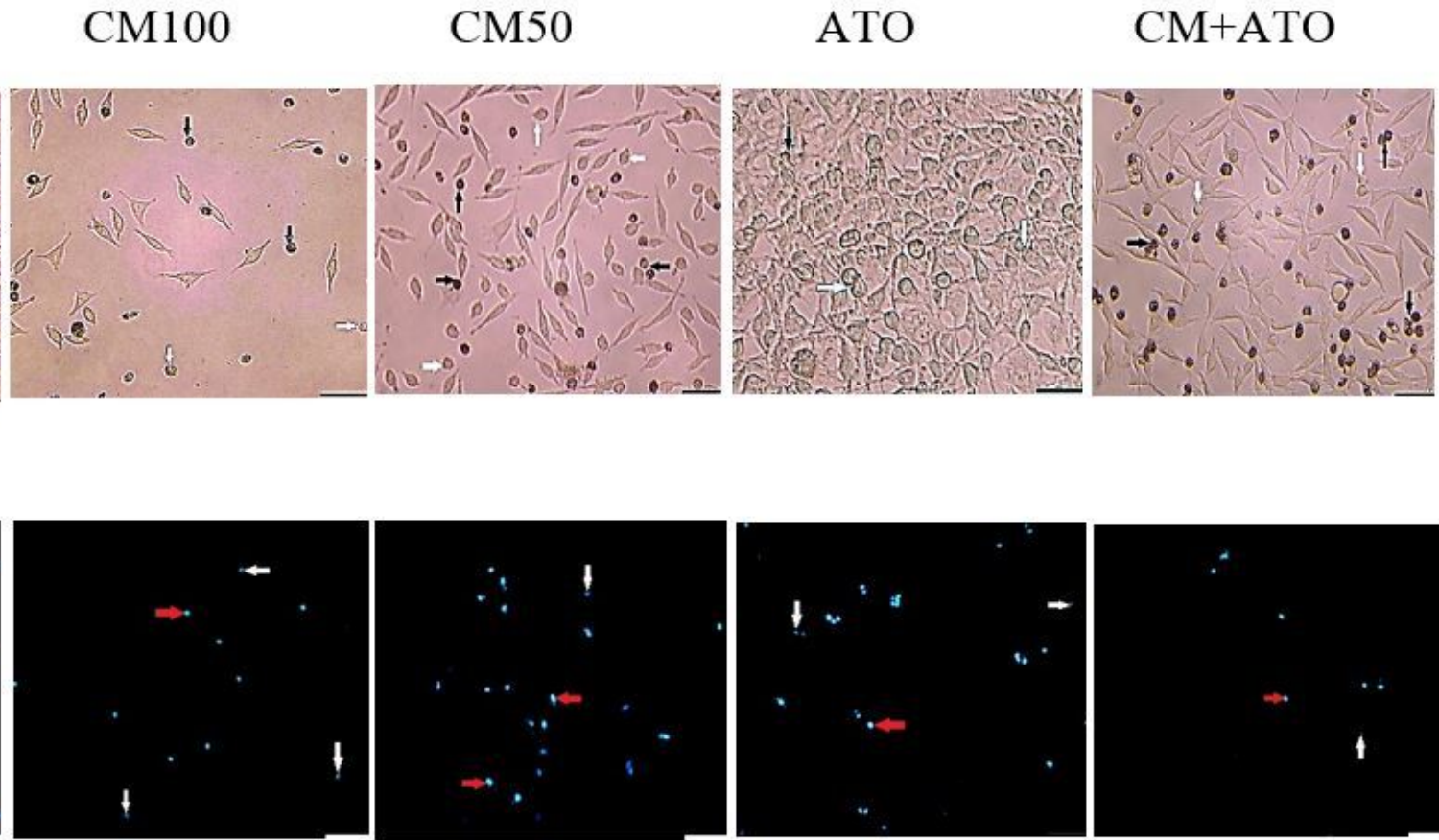

ATO

G
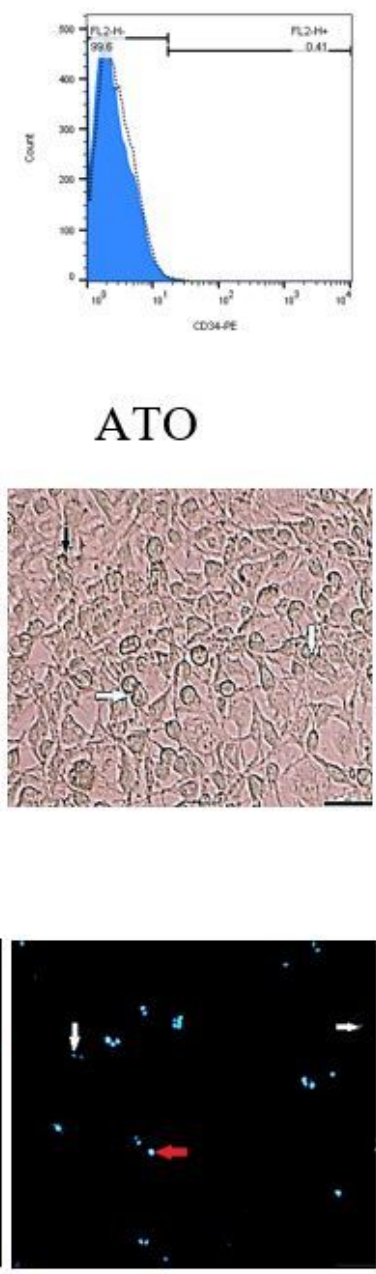

$\mathrm{CM}+\mathrm{ATO}$

$\mathrm{H}$
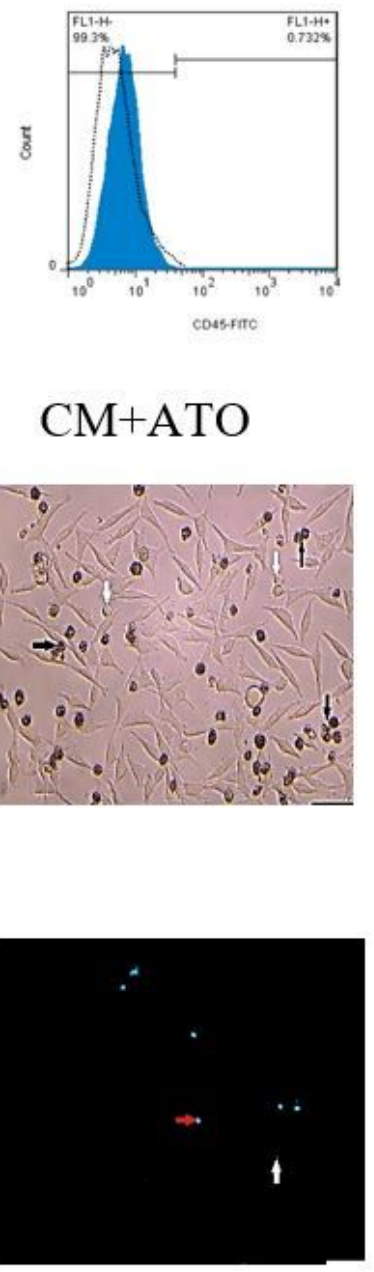

\section{Figure 1}

A to $\mathrm{H}$ : Isolation and identification of human umbilical cord mesenchymal stem cells (hUCMSCs). A: Fibroblastlike morphology and spindle-shaped plastic-adherent hUCMSCs after 14 days of initial culture, sprouted from Wharton's jelly pieces (passage 0). B: Osteogenic Alizarin Red staining and C: Adipogenic Oil Red O staining showed differentiation after 21 days' induction. Images were photographed by an inverted light microscope. Scale bar:100 $\mu \mathrm{m}$. Magnification: $\times 20$ objective lens. D, E, F: Flow cytometry histogram chart of the surface positive and G, H: negative CD markers of hUCMSCs at passage3. I to J: Untreated and treated MCF7 morphological changes after $48 \mathrm{hrs}$. I: Images were photographed by an inverted light microscope. White arrows showed the cell shrinkage; Black arrows showed the nuclear chromatin condensation(pyknosis) due to apoptosis. J: Images detected with DAPI staining and photographed by fluorescence microscope. Red arrows 


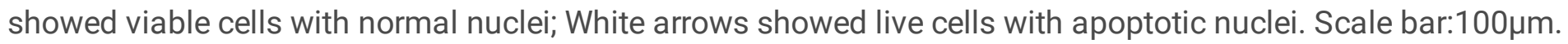
Magnification: $\times 20$ objective lens.

A

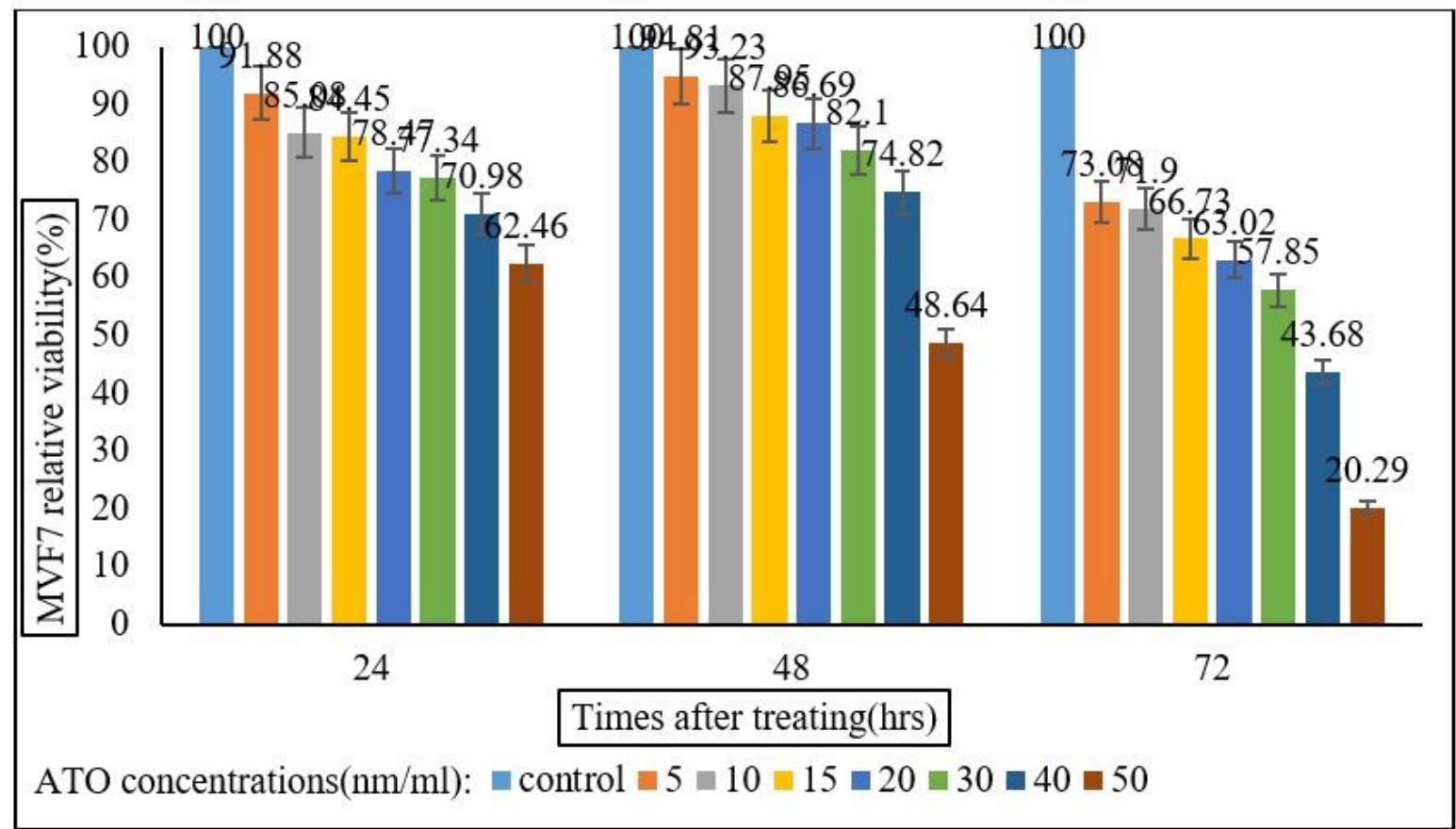

B

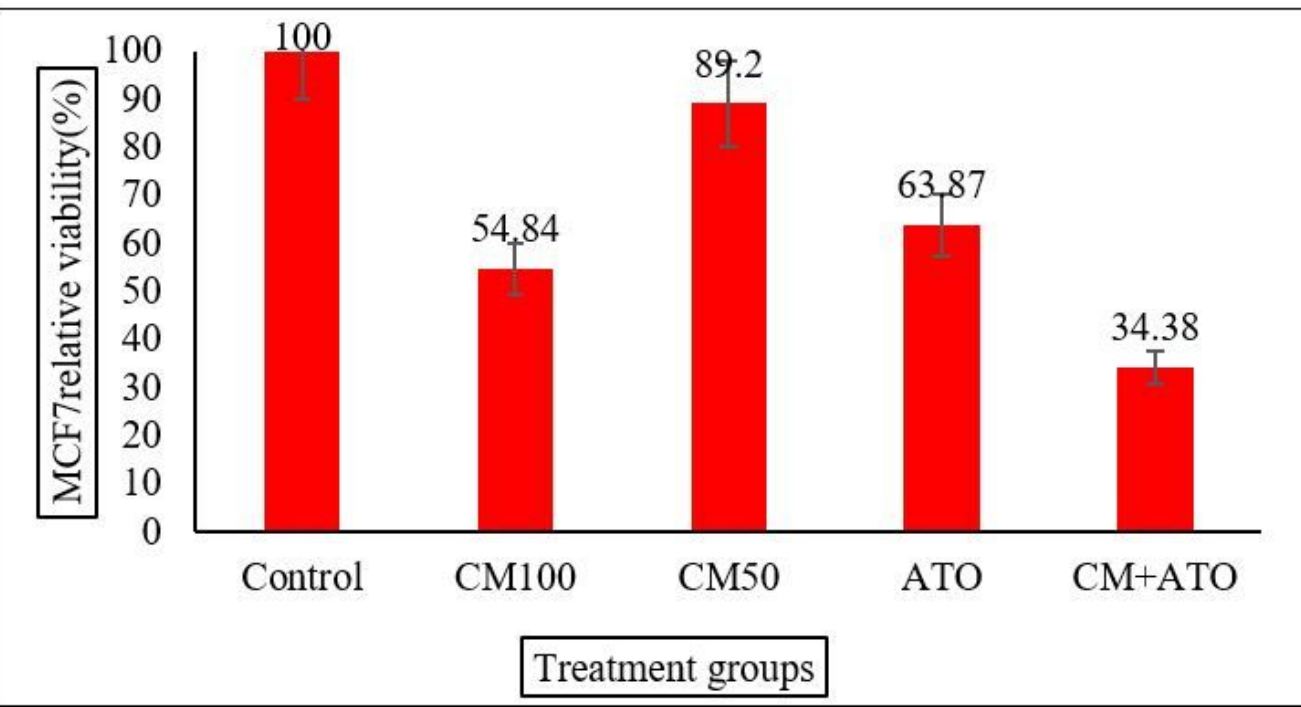

Figure 2

Relative cells viability of MCF7 by MTT assay. A: Clustered column chart of MCF7 cell relative viability after 24,48 and 72 hrs treating with different concentrations of ATO compared to control group. Differences between mean relative viability of treated groups with different ATO concentrations are significant ((One-Way ANOVA test sig $<0.05$ ). B: Clustered column chart of MCF7 cell relative viability after 48 hrs treating with CM50, CM 100, ATO IC50 value $(18 \mathrm{~nm} / \mathrm{ml})$, and CM50+ATO $(9 \mathrm{~nm} / \mathrm{ml})$ compared to control group. Differences between mean relative 
viability of treated groups are significant (one-way ANOVA and post hoc multiple comparisons on the basis of Tukey's HSD test sig $<0.05)$. Values are mean \pm SD $(n=3)$.
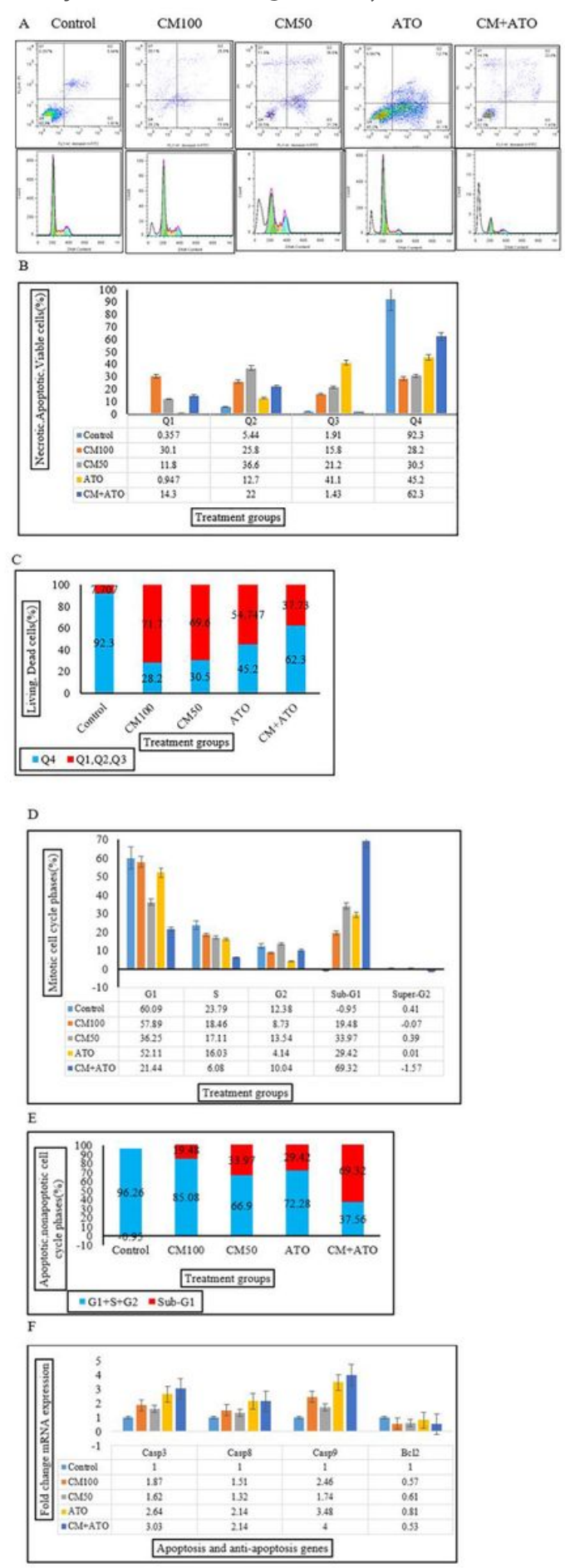

\section{Figure 3}

Identification of apoptosis by Annexin V/PI double staining with flow cytometry assay. A: Scatter plot of logarithmically amplified fluorescence signals demonstrated the typical apoptotic and necrotic (Q1, Q2, Q3 quadrants) cell population increasing and viable (Q4 quadrant) cells decreasing in treated groups. The frequency histograms of mitotic cell cycle phases showed that the sub-G1 (apoptosis) phase in the control group was negative and increased following treatment with $\mathrm{CM}$ and ATO. B: Clustered column chart of necrotic/late apoptotic (Q1), necrotic (Q2), early apoptotic(Q3), and viable cell(Q4) quadrants frequencies. The quadrant 
frequencies in control and treated groups are not equal (Chi-Square Asymp. Sig<0.05). C: Differences between dead cell (Q1+Q2+Q3) and living cell (Q4) quadrants in every treated group are significant in comparison with control group (2-sided Exact sig in Pearson Chi-Square test<0.05). D: Clustered column chart of mitotic cell cycle phases. The mitotic cell cycle phases in control and treated groups are not equal (Chi-Square Asymp. Sig<0.05). E: The sub-G1 phase and the sum of other phases (G1, S, G2) frequencies differences between treated and control groups are significant (2-sided Exact sig in Pearson Chi-Square test $<0.05)$. Data represented are means \pm SD of three independent experiments $(n=3)$. F: Clustered column chart of quantitative real-time PCR for detection of apoptosis and anti-apoptosis genes against controls over 48 hours. Results are expressed as mean of fold change in expression of mRNA levels compared to control condition. The caspase3, caspase8, and caspase 9 apoptosis-related genes were up-regulated in treated cells, but Bcl-2 was downregulated. Each assay was normalized to housekeeping gene Beta2 Microglobulin. Differences between treated groups are significant (One-Way ANOVA test sig $<0.05$ ) compared to untreated cells. Data represented are means \pm SD of three independent experiments $(n=3)$.
A Control
CM100
CM50
ATO
$\mathrm{CM}+\mathrm{ATO}$
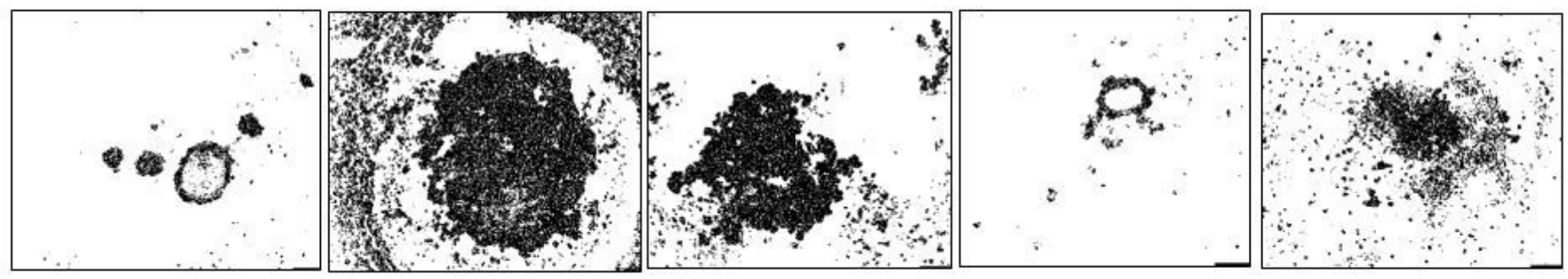

B

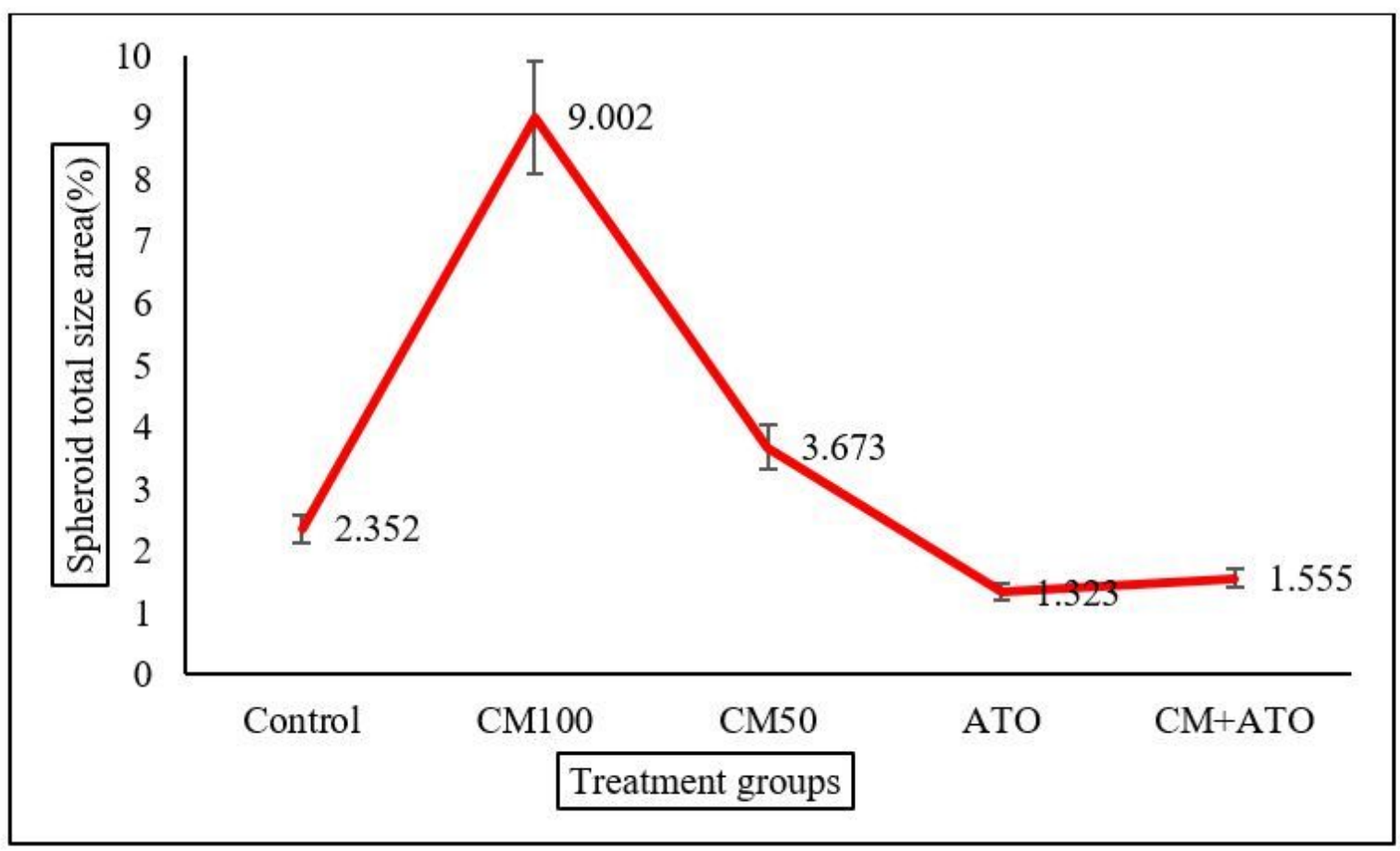




\section{Figure 4}

Three-dimensional spheroid culture of MCF7 after 7 days in hanging drop growth assay either in untreated or treated groups. A: Representative sample pictures of each group. Images were photographed by an inverted light microscope and analyzed by Image J software. Scale bar:100 $\mu \mathrm{m}$. Magnification: $\times 5$ objective lens. B: The line chart of spheroids' total size area (Mean \pm SD) of three independent measurements in control and treated groups. Differences between treated groups compared to untreated groups were significant (One-Way ANOVA test sig $<0.05)$.
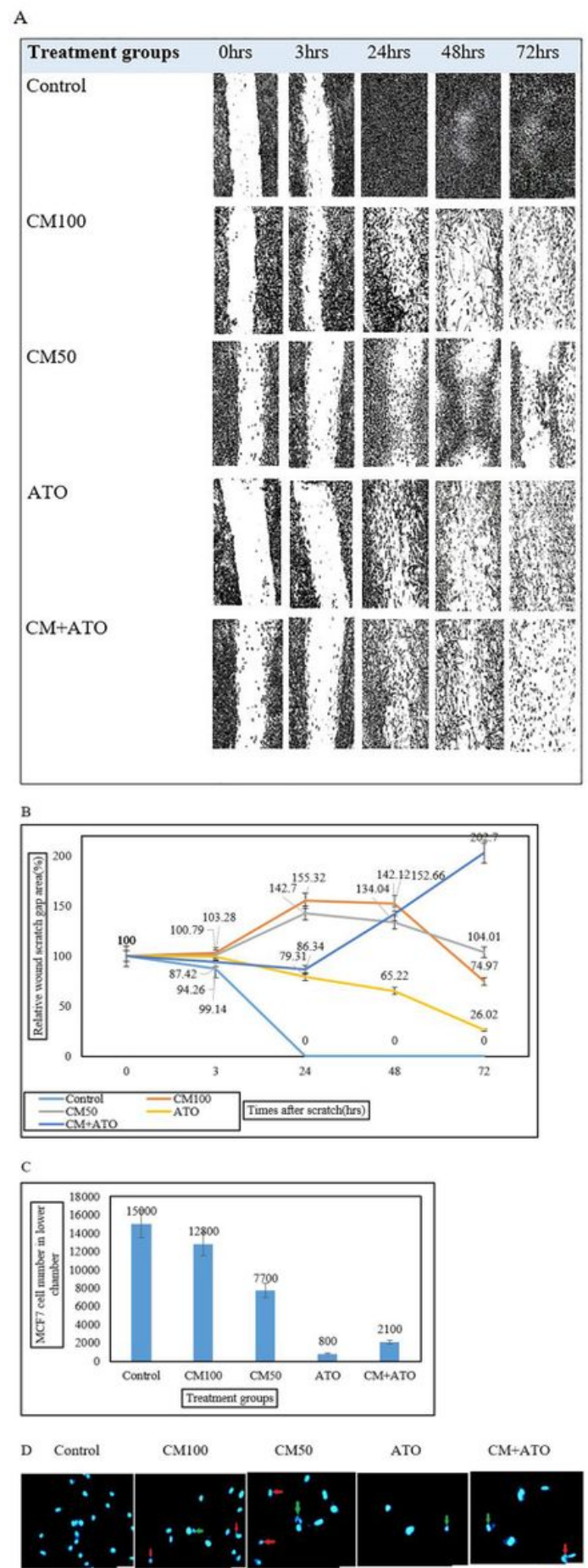

Figure 5 
A and B: Scratch-wound assay of MCF7 cells in control and treated groups after similar interval times. A: Representative sample pictures of each group. Images were photographed by an inverted light microscope and analyzed by ImageJ software. Scale bar:100 $\mathrm{mm}$ (In control, $72 \mathrm{hrs}$ ). Magnification: $\times 5$ objective lens. The white dots appeared in the center of scratch after $48 \mathrm{hrs}$ could be the cell necrosis because of very proliferative impacted cells. B: Line chart of relative wound scratch gap area. Differences between treated groups compared to untreated groups were significant (One-Way ANOVA test sig <0.05). Data represented are means \pm SD of three independent experiments $(n=3)$. C and D: Trans-well migration assay of MCF7 cells after 48 hrs incubation. C: Clustered column chart of quantification of MCF7cells migrating toward the chemo-attractant in the lower chamber. Values are mean \pm SD of independent experiments $(n=3)$. Differences among the treated groups compared to untreated groups were significant (One-Way ANOVA test sig <0.05). D: Representative sample photographs of cell migrated staining with DAPI on the lower chamber of each group and observed using fluorescence microscope. Untreated cells showed uniformly stained nuclei representing viable cells (in the Control image). Appearance of chromatin condensation (White arrows) and DNA fragmentation (Red arrows) are signs of apoptosis of cells (In CM and ATO treated images). Magnification: $\times 40$ objective lens. Scale bar: 100 $\mu \mathrm{m}$.

\section{Supplementary Files}

This is a list of supplementary files associated with this preprint. Click to download.

- Appendixes.docx 